\title{
Acessibilidade e indicadores de emprego, tempo e distância de viagens: uma análise da Região Metropolitana de Goiânia
}

Ana Stéfany da Silva Gonzaga

http://lattes.cnpq.br/5966743639239312

Faculdade de Artes Visuais, Universidade Federal de Goiás, Brasil

\author{
Érika Cristine Kneib \\ http://lattes.cnpq.br/2807145158226533 \\ Faculdade de Artes Visuais, Universidade Federal de Goiás, Brasil
}

Recibido: 15 de enero de 2019. Aceptado: 30 de agosto de 2019

\section{Resumo}

Nas metrópoles brasileiras, a ocorrência de deslocamentos pendulares constantes é característica de grande relevância, mas que também gera grandes desafios. Para os gestores públicos de cada um dos municípios componentes de regiões metropolitanas, é de fundamental importância conhecer as necessidades e a disponibilidade de atividades no território, bem como o perfil dos deslocamentos de suas populações. Com isso, torna-se possível desenvolver diagnósticos coerentes com a realidade de cada município e também compreender o funcionamento da região metropolitana como um todo. Diante de tal abordagem e tendo a Região Metropolitana de Goiânia (RMG) como objeto de estudo, este trabalho tem como objetivo explorar o uso de indicadores de acessibilidade como ferramentas que auxiliam o planejamento e a gestão urbana a partir de um estudo concentrado em características como o tempo gasto e a distância percorrida em viagens, bem como a oferta de empregos nos diversos municípios. Dentre os resultados obtidos neste trabalho está a identificação de características que indicam a falta de prioridade ao transporte público frente aos modos motorizados individuais, o que agrava as condições de acessibilidade e mobilidade metropolitanas. Além disso, observa-se uma concentração de atividades que provoca certo desequilíbrio ao contribuir para condições de saturação em Goiânia (capital do estado de Goiás) enquanto outros municípios apresentam características de cidade dormitório.

Palavras-chave: Indicadores de acessibilidade. Transporte público. Transporte metropolitano. 


\title{
Accessibility and employment, travel time and distance indicators: an analysis of the Goiânia Metropolitan Region
}

\begin{abstract}
In the Brazilian metropolis, the occurrence of constant commuting is a feature of great relevance, but also presents great challenges. For the public managers of each of the municipalities that are components of metropolitan areas, it has fundamental importance to know the needs and availability of activities in the territory, as well as the profile of the displacements of their populations. With this, it becomes possible to develop diagnoses consistent with the reality of each municipality and also to understand the functioning of the metropolitan region as a whole. In view of such an approach and having the Metropolitan Region of Goiânia (RMG) as an object of study, this work is inserted with the objective of exploring the use of accessibility indicators as tools that help planning and urban management from a concentrated study in characteristics such as the time spent and the distance traveled in trips, as well as the offer of jobs in the several municipalities. Among the results obtained in this work is the identification of characteristics that indicate the lack of priority to public transport in relation to individual motorized modes, which aggravates the conditions of accessibility and urban mobility in metropolitan relations. In addition, there is a concentration of activities that causes a certain imbalance by contributing to saturation conditions in Goiânia (capital of the state of Goiás) while other municipalities present characteristics of a dormitory city.
\end{abstract}

Keywords: Accessibility indicators. Public transportation. Metropolitan transport.

Palabras clave: Indicadores de accesibilidad. Transporte público. Transporte metropolitano.

\section{Introdução}

Em grandes centros urbanos, os deslocamentos de longas distâncias fazem parte do cotidiano de suas populações. O desequilíbrio entre as atividades disponíveis nas diversas localidades, bem como a política de preço da terra são alguns dos fatores que dificultam à população uma moradia mais próxima ao trabalho. $\mathrm{O}$ tempo gasto nos trajetos casa-trabalho suprime das pessoas percentuais expressivos de horas em seus dias, que poderiam ser destinadas às atividades mais produtivas ou até mesmo para lazer ou descanso. Além disso, o tempo gasto em deslocamentos urbanos é também, dentre outros aspectos, um fator que interfere significativamente na escolha de um modo de transporte.

Uma pesquisa realizada pela Associação Nacional dos Transportes Públicos - ANTP revelou que, entre os anos de 2015 e 2016, cerca de três milhões de pessoas por dia deixaram de usar os ônibus. O levantamento foi realizado nas capitais brasileiras que, juntas, representam 37\% da demanda de passageiros de ônibus de todo o Brasil (Belo Horizonte, Curitiba, Fortaleza, Goiânia, Porto Alegre, Recife, Rio de Janeiro, Salvador e São Paulo). Dentre os vários motivos que têm provocado a ocorrência deste fenômeno está a discrepância entre os tempos de viagem gastos pelo usuário de transporte público e dos modos individuais motorizados (ANTP, 2018).

Ao comparar os tempos de viagens por veículos motorizados individuais e por transporte público, observa-se uma grande disparidade. Segundo a ANTP, em 2014, viagens em transporte coletivo representavam $69 \%$ do tempo consumido nos deslocamentos; enquanto para usuários de transporte individual esse percentual 
era de 31\% (ANTP, 2018). Essa realidade tem contribuído negativamente para as condições de mobilidade e acessibilidade das populações.

Cabe destacar que enquanto um ônibus que transporta até 72 pessoas ocupa $30 \mathrm{~m}^{2}$, a mesma quantidade de pessoas ocupa $1.000 \mathrm{~m}^{2}$ se estas utilizarem 60 carros (com taxa média de ocupação de 1,2 pessoas por carro) (Bertucci, 2011). O impacto que o automóvel exerce sobre a capacidade da infraestrutura viária, somado à insuficiência de estratégias que priorizem o transporte público são fatores que afetam negativamente as condições de mobilidade e acessibilidade das pessoas. Além disso, as populações com menor poder aquisitivo e que ainda fazem uso do transporte público são as mais prejudicadas.

A existência desse cenário negativo é evidente, perceptível no próprio dia a dia de milhões de cidadãos brasileiros. No entanto, a mudança para um contexto mais justo e igualitário requer um olhar mais atento e aprofundado sobre as características de cada localidade. Além disso, também merece atenção o modo como suas populações se dispõem e se deslocam sobre os territórios. Conhecer a fundo o panorama de uma localidade contribui para a implantação de ações pautadas em um planejamento coerente e mais efetivo. No âmbito legislativo cabe destacar uma significativa evolução no que tange às diretrizes e normas estabelecidas para as cidades brasileiras expressas, por exemplo, no Estatuto da Metrópole e na Lei de Mobilidade.

Criado em 2015 sob a forma da Lei 13.089, o Estatuto da Metrópole dispõe sobre o planejamento, a gestão e a execução das funções públicas de interesse comum em regiões metropolitanas. Diretrizes e normas gerais voltadas para a governança interfederativa apontam para o compartilhamento das responsabilidades entre os municípios e, assim, mostram uma possibilidade de avanço significativo quanto ao tratamento das relações metropolitanas no Brasil. Ao tornar obrigatória a elaboração de um Plano de Desenvolvimento Integrado, o Estatuto da Metrópole estabelece através deste a importância de um instrumento fundamental para a garantia de processos permanentes gestão, planejamento e viabilização econômico-financeira que conduzam o desenvolvimento territorial estratégico das regiões metropolitanas brasileiras (Presidência da República Brasileira, 2015).

Somado ao Plano de Desenvolvimento Integrado deve estar, ainda, o Plano de Mobilidade, instrumento obrigatório segundo a Lei 12.587, de 3 de janeiro de 2012. Este, por sua vez, deve contribuir para o acesso universal à cidade, bem como o planejamento e a gestão democrática dos modos de transporte, serviços e infraestruturas para garantia dos deslocamentos de pessoas e cargas no território dos municípios (Presidência da República Brasileira, 2012). Nesse sentido, destacam-se os Planos de Desenvolvimento Integrado e os Planos de Mobilidade como instrumentos fundamentais para a garantia do compartilhamento de responsabilidades no que tange às relações metropolitanas na busca por melhores condições de mobilidade e acessibilidade às populações.

Dessa forma, o uso de indicadores se faz de suma importância para a construção de um diagnóstico preciso, que expresse a situação das diversas localidades e, a partir dos parâmetros e objetivos que se deseja alcançar, se obtenham melhorias através dos contínuos processos de planejamento e gestão metropolitana. Portanto, neste trabalho é explorado o potencial de indicadores como ferramenta auxiliar na elaboração de diagnósticos da acessibilidade a partir dos fatores tempo e distância, conhecidos como fatores de impedância da acessibilidade. Para tal, são utilizados os indicadores de Allen et al. (1993), que possibilitam avaliar a acessibilidade dos municípios em sua totalidade, como um conjunto; e de Hansen (1959), um indicador do tipo gravitacional, tendo o emprego como o fator de oportunidade que contribui para a geração de viagens. 


\section{Acessibilidade e o contexto da escala macro}

A acessibilidade urbana é trabalhada no âmbito de diversos temas e disciplinas. No contexto da Geografia, por exemplo, a acessibilidade urbana se aplica em estudos sobre transformações socioespaciais e nas relações entre elementos como transporte, renda, uso e valorização de terrenos urbanos e o crescimento das cidades (Cardoso e Matos, 2007). Para Veras et al. (2016), além do espaço urbano, a acessibilidade urbana também contempla a organização da sociedade, sendo que, ao conectar os diversos pontos da cidade entre si, os sistemas de transporte se inserem como um dos principais condicionantes de tal organização social urbana (Veras at al., 2016). Nesse sentido, Cardoso e Matos (2007) destacam que as deficiências na acessibilidade urbana poderiam ser minimizadas através de estratégias de redimensionamento das relações entre transporte e uso do solo a fim de promover o desenvolvimento equilibrado e sustentável do espaço urbano.

O conceito de acessibilidade está, portanto, diretamente relacionado ao de mobilidade urbana. Enquanto este diz respeito às condições de deslocamento das pessoas nos espaços das cidades, a acessibilidade está mais relacionada aos elementos que conferem às pessoas a mobilidade. Associada à mobilidade, a acessibilidade atua como uma medida potencial que oferece expressivo impacto sobre as possibilidades de ocorrência de deslocamentos (Sales filho, 1998).

Para este conceito é importante destacar que não se deve confundir com a acessibilidade universal que, de acordo com a NBR 9050 (ABNT, 2015) é definida como a possibilidade e condição de alcance, percepção e entendimento para que todas as pessoas, independentemente de suas condições físicas, possam utilizar com segurança e autonomia as edificações, o espaço, o mobiliário, equipamentos urbanos e outros.

Neste trabalho, o conceito de acessibilidade está inserido na área de transporte e mobilidade e se refere, em resumo, à facilidade de acesso entre determinado ponto e os demais componentes de uma rede urbana (Taaffe et al., 1996).

Para Raia Junior et al. (1997), a acessibilidade é o esforço que os indivíduos desempenham para transpor determinada separação espacial, com o objetivo de exercer suas atividades cotidianas. Jones (1981) afirma que a acessibilidade está relacionada com a oportunidade ou o potencial para que as pessoas possam desenvolver suas atividades. Segundo o autor, o sistema de transporte e o uso do solo são os elementos que disponibilizam esse potencial ou oportunidade. Para Ingram (1971), a acessibilidade se relaciona com a forma de superar obstáculos espaciais. Estes, por sua vez, se constituem a partir de características próprias de determinado local. Fatores como tempo e distância podem contribuir significativamente para medir a acessibilidade. Segundo o Ministério das Cidades (Mcidades, 2008), a acessibilidade é definida como a facilidade, medida em distância, tempo e custo, que as pessoas têm de alcançar, com autonomia, destinos desejados na cidade. Apesar de estar relacionada a diversos fatores, a acessibilidade depende fundamentalmente da articulação entre os transportes e o uso do solo (Mello, 2015).

Cabe também destacar que as características dos indivíduos e a condição de estarem estes empregados ou não são fatores que impactam significativamente na mobilidade dessas pessoas. Nesse sentido, Motte-Baumvol et al. (2015) apontam ainda a segregação espacial, bem como a existência de barreiras físicas, simbólicas ou de percepção como fatores que interferem sobre as condições de mobilidade e acessibilidade das pessoas.

Portugal (2017) descreve as cinco dimensões do ambiente construído (5 D’s), propostas por Cervero (2009 apud Portugal, 2017), dentre as quais estão: densidade, diversidade, 
desenho urbano, disponibilidade de transporte público e destinos acessíveis. Segundo o autor, essas dimensões têm influência expressiva na promoção da mobilidade sustentável ao determinar condições de acessibilidade favoráveis ao transporte público e ao transporte não motorizado. Ao se articularem com uma estação de transporte público de maior capacidade, contribuem para a promoção de modalidades sustentáveis. Nesse sentido, é possível envolver também as escalas meso e macro, sendo fundamental a articulação entre o uso do solo e uma rede de transportes com capacidade de prover acessibilidade em todas as escalas (Portugal, 2017).

A Figura 1, a seguir, esquematiza a relação entre as diferentes escalas urbanas e a multimodalidade nos sistemas de transporte. Observa-se que, para cada escala, as viagens apresentam modais diferentes, o que busca compatibilizar as distâncias percorridas com seus respectivos modos de transporte mais adequados. A Figura 1 apresenta três diferentes escalas urbanas denominadas micro, meso e macro. Na escala micro, as relações entre os deslocamentos estão pautadas nas curtas distâncias, possíveis e preferencialmente realizadas a pé ou por bicicleta. Na escala meso, as distâncias são maiores quando comparadas à micro. Nesta deve predominar o uso da bicicleta e do transporte público de menor capacidade, tais como o realizado através de ônibus das linhas alimentadoras (Mello, 2015). Em ambas as escalas citadas, destaca-se a importância da autonomia das localidades bem como uma oferta de infraestrutura de transporte e de atividades compatível com as necessidades dos moradores. Tais condições contribuem, portanto, para o desestímulo ao uso de automóveis (Portugal, 2017).

A escala macro, por sua vez, é a mais abrangente e envolve as maiores distâncias como, por exemplo, entre municípios em uma região metropolitana (Mello, 2015). O transporte público de maior capacidade é o modo que deve prevalecer nos deslocamentos desta escala (Kneib, 2014), dentre os quais estão os sistemas de BRT (Bus Rapid Transit), VLT (Veículo Leve sobre Trilhos), metrôs e trens (ITDP, 2016). Além disso, a integração multimodal permite maior facilidade de acesso aos diversos destinos pelo território como um todo (Portugal, 2017), bem como o tratamento integrado das diversas escalas urbanas.

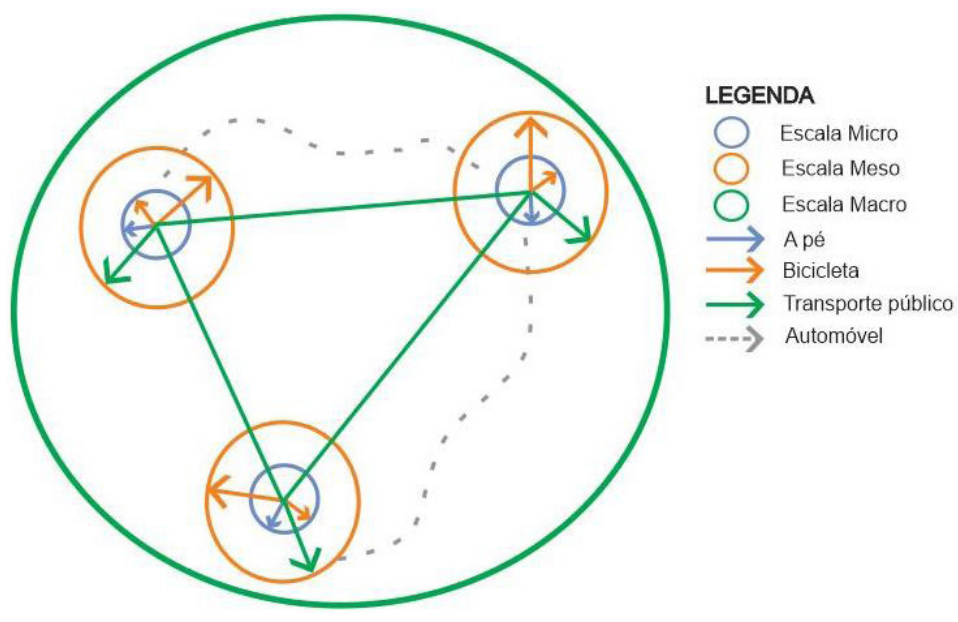

Figura 1. Esquema sobre a relação entre as escalas urbanas e a multimodalidade. Fonte: adaptado de Kneib, 2014.

Neste trabalho, a fim de analisar as relações espaciais entre os municípios que compõem a Região Metropolitana de Goiânia, a acessibilidade foi avaliada a partir de indicadores de emprego, tempo e distância de viagens. De acordo com a definição de Ingram (1971), 
características inerentes a cada município foram abordadas como obstáculos espaciais a serem superados. Sendo assim, os elementos de avaliação da acessibilidade na RMG foram pautados no tempo gasto e na distância percorrida em viagens entre os municípios. Por outro lado, a oferta de empregos nos municípios foi analisada como fator atrativo de viagens.

\section{Tempo e distância como fatores de impedância da acessibilidade}

Apesar de tempo e distância serem, matematicamente grandezas proporcionais; podem não apresentar tal relação quando se trata de transportes urbanos. Conforme Teixeira Filho (2009), além da distância percorrida, outros fatores como as condições das vias e dos serviços de operação e outros aspectos referentes às condições de velocidade dos veículos são alguns dos principais motivos de alterações significativas na relação entre tempo e distância.

Para Allen (1993), tempo e distância são medidas de fricção da acessibilidade. Ao serem analisados podem apresentar uma medida que caracteriza o esforço necessário para se superar a separação espacial entre dois pontos. No entanto, as relações entre a infraestrutura de transporte, o espaço urbano, a população e as atividades por ela desempenhadas influenciam os indivíduos em seus processos de tomada de decisão sobre a realização de viagens no espaço urbano. Essa inter-relação, por sua vez, é de fundamental importância no planejamento de transportes (Santos, 2009).

A escolha dos modos de transporte a serem utilizados pelos indivíduos envolve aspectos tais como os referentes aos destinos, horários de funcionamento, rotas de ligação e seus tempos de viagens para os diferentes modos de transporte disponíveis. De acordo com Ettema (1996, apud Santos, 2009), essas informações contribuem significativamente para a determinação de efeitos espaciais decorrentes das escolhas de atividades, destinos e modos de transporte.

Segundo Ortúzar e Willumsen (2001), a decisão sobre a escolha do modo de transporte depende de três diferentes características principais; são elas: dos usuários; da viagem; do sistema de transportes. Este, por sua vez, envolve dois aspectos mais significativos: o tempo e o custo da viagem. Segundo Mello (2015), a incompatibilidade de horários entre a disponibilidade dos serviços de transporte e as necessidades das pessoas faz com que o tempo seja um fator de barreira. Isso também pode ocorrer quando o tempo de deslocamento é superior ao máximo aceitável. Para Ferraz e Torres (2001), uma avaliação comparativa entre os tempos de viagem em transporte público e em veículo motorizado individual oferece informações relevantes sobre a qualidade do sistema de transporte público.

Quanto à relação espaço-tempo, observa-se que em áreas metropolitanas o tempo médio de deslocamento é significativamente mais elevado. Em 2007, o Ministério das Cidades (2007) apontou que os problemas e as necessidades vivenciados em cidades-polo muito se diferem das cidades periféricas. Enquanto as cidades-polo, ao apresentarem um excesso de oferta, adquirem problemas como a saturação e o congestionamento dos sistemas de transporte; nas cidades periféricas se encontram precariedade da infraestrutura, falta de oferta de transporte público e tempo excessivo gasto em deslocamentos. Nesse sentido, uma pesquisa realizada em 2009 também identificava que o tempo médio gasto em deslocamentos casa-trabalho em áreas metropolitanas foi 63\% maior que em áreas não metropolitanas no Brasil (Pereira e Schawanen, 2013 apud Mello, 2015).

Nesse sentido, análises baseadas em fatores como tempo e distância contribuem para que sejam identificadas características relacionadas à geração de impedâncias às 
localidades. Os cenários pautados nestes fatores permitem a compreensão das relações existentes entre municípios componentes de uma região metropolitana. Apesar de relativamente simples e de fácil aquisição, os referidos dados, quando trabalhados e analisados de forma adequada, gerando informação relevante, oferecem informações de expressiva importância nos processos de planejamento e gestão urbana.

\section{Indicadores de acessibilidade}

Diante do desafio de buscar informações que caracterizem a acessibilidade de determinado contexto urbano e, a partir disso, possibilitar o desenvolvimento de um diagnóstico que irá pautar o planejamento e a gestão de cidades, os indicadores se inserem como ferramenta fundamental. Este é um instrumento que possibilita obter informações sobre determinada realidade (Mitchell, 1996), sendo que um bom indicador deve possibilitar fácil entendimento, além de uma quantificação estatística e lógica coerente (Mueller et al., 1997). Sendo assim, os indicadores possibilitam a compreensão de conceitos abstratos e de difícil mensuração ao transformá-los em uma linguagem operacional e mensurável. Dessa forma, permite revelar tendências e panoramas, bem como a identificação de deficiências (Costa, 2008).

Um indicador é, portanto, composto pela junção de diversos elementos que, ao serem analisados, resultam em determinado valor agregado final que permite visualizar o estado de um sistema ou fenômeno. A obtenção do índice se dá através de procedimentos de cálculo tendo indicadores como variáveis (Shields et al., 2002).

O Ministério das Cidades (2007) recomenda que, na elaboração do Plano Diretor de Transporte e da Mobilidade haja a concepção, implantação e manutenção de um Sistema de Avaliação Permanente da Qualidade do Transporte Coletivo e de Indicadores de Trânsito. Para este sistema, devem ser definidos os indicadores a serem trabalhados, bem como sua periodicidade de apuração, fontes de informação, aplicações imediatas e formas de divulgação.

No contexto do transporte público, ao apontar valores excessivos de tempo gasto em deslocamentos, um indicador de acessibilidade pode revelar certa imobilização física de passageiros em determinados momentos (Barat, 1978). Por sua vez, os indicadores baseados no fator distância são conhecidos como medidas de conectividade e tratam de dados de fácil obtenção, operacionalização e interpretação dos resultados (Bruinsma e Rietveld, 1998). Nessa relação, cabe ressaltar que sistemas de transporte onerosos em relação ao tempo gasto ou à distância percorrida podem contribuir significativamente para que os passageiros escolham outro modal para seus deslocamentos ou, até mesmo, para que deixem de realizar atividades.

\section{Análise da macroacessibilidade na região metropolitana de Goiânia}

Goiânia é a capital do estado de Goiás, localizada no centro-oeste brasileiro. Até o ano de 1999, 11 municípios faziam parte da RMG, sendo eles Abadia de Goiás, Aparecida de Goiânia, Aragoiânia, Goianápolis, Goiânia, Goianira, Hidrolândia, Nerópolis, Santo Antônio de Goiás, Senador Canedo e Trindade, totalizando 1.639.516 habitantes em um território de cerca de $4.000 \mathrm{~km}^{2}$. No ano de 2004 foi acrescido à RMG o município de Bela Vista de Goiás e em 2005, Guapó; o que, somado a estes e aos aumentos populacionais dos demais municípios, elevou a população da RMG para 1.934.771 
habitantes em território de $5.796,942 \mathrm{~km}^{2}$. No ano de 2010, foram incluídos mais 7 municípios: Bonfinópolis, Brazabrantes, Caldazinha, Caturaí, Inhumas, Nova Veneza e Terezópolis de Goiás, totalizando assim 20 municípios na RMG, com população de 2.173.115 habitantes e território de $7.341,849 \mathrm{~km}^{2}$. Esta era a configuração da RMG à época do desenvolvimento deste trabalho, momento em que estava em vigor a Lei Complementar No 27, de 1999 (Prefeitura de Goiânia, 2012). Em 2018, através da Lei Complementar No 139, de 2018, o município de Inhumas deixou de fazer parte da RMG e foi acrescido o município de Santa Bárbara de Goiás (Estado de Goiás, 2018). Em sua alteração mais recente, realizada em maio de 2019, Inhumas voltou a fazer parte da RMG, totalizando assim 21 municípios (Estado de Goiás, 2019). A Figura 2, a seguir mostra as alterações ocorridas na RMG entre os anos de 1999 e 2010.

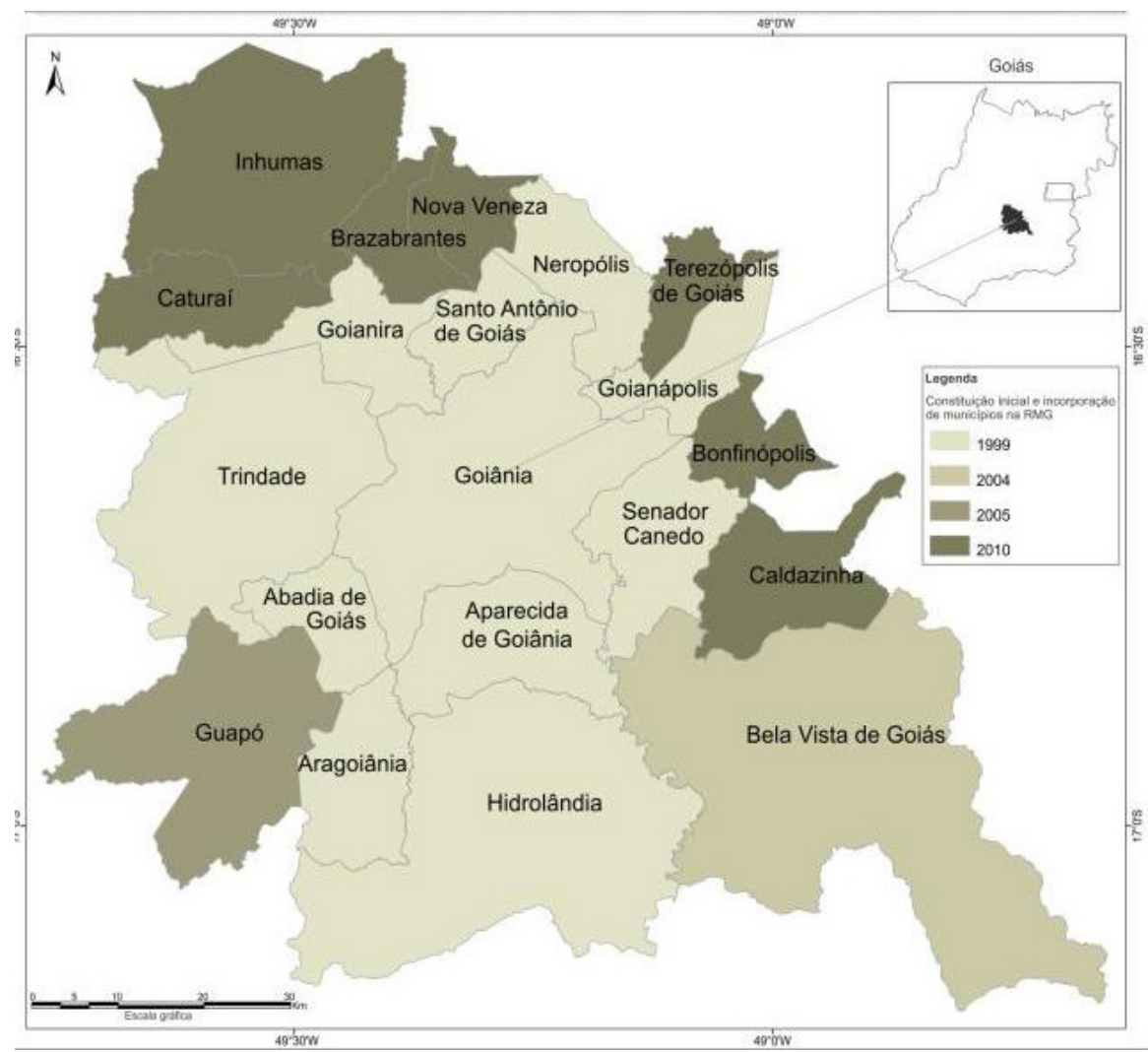

Figura 2. Alterações na composição da RMG entre 1999 e 2010. Fonte: Secima, 2018.

Na RMG o serviço de transporte público coletivo é ofertado pela RMTC - Rede Metropolitana de Transporte Coletivo de Goiânia - que, por sua vez, tem a CMTC - Companhia Metropolitana de Transportes Coletivos - como gestora pública. Os municípios de Caturaí e Inhumas não são atendidos pela RMTC, ou seja, a referida rede se aplica em dezoito dos vinte municípios que compreendem a RMG. O referido sistema é de modelo tronco-alimentado, possui 19 terminais de integração físico-tarifária e um corredor exclusivo denominado Eixo Anhanguera. Este é o principal corredor exclusivo da região e atende aos municípios de Trindade, Goianira, Goiânia e Senador Canedo (RMTC, 2016).

O Plano Diretor de Goiânia prevê uma Rede Estrutural de Transporte Coletivo composta por corredores exclusivos, preferenciais, estações de integração, de conexão e de modais; bem como ciclovias, bicicletários e estacionamentos. Também é prevista a implantação de seis corredores, articulados com corredores metropolitanos e 
integrantes da RMTC. Dentre os quais estão: Corredor Anhanguera; Corredor Goiás; Corredor Mutirão; Corredor T-9; Corredor T-7 e Corredor Leste-Oeste. Destes, é operante apenas o Corredor Anhanguera, sendo necessária sua ampliação e remodelação. O Corredor Goiás foi parcialmente implantado, necessita ainda de ampla reformulação a partir do projeto para o BRT (Bus Rapid Transit) no referido eixo. Dos vinte corredores preferenciais previstos no Plano Diretor de Goiânia, apenas três foram implantados (Prefeitura de Goiânia, 2007). A Figura 3, a seguir, ilustra a distribuição espacial de algumas das principais linhas de ônibus que integram a RMG através do transporte coletivo.
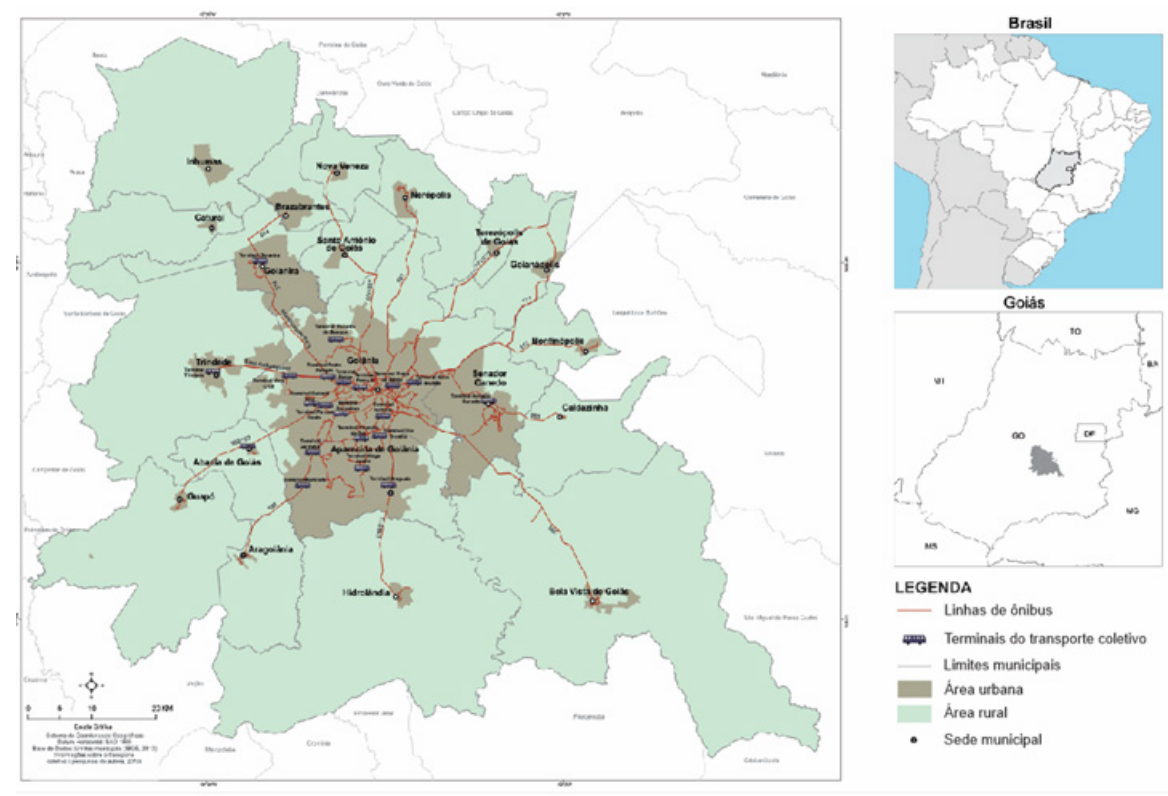

Figura 3. Linhas de ônibus da Região Metropolitana de Goiânia - 2016. Fonte: própria.

O Plano Diretor de Goiânia oferece um aparato de diretrizes que dão ao transporte público sua devida importância na Rede Estrutural de Transporte Coletivo e, assim, faz uso dos corredores para alcançar benefícios como o aumento da velocidade operacional dos ônibus e o consequente ganho de tempo ao usuário. Na prática, a ausência ou incompletude destes corredores provoca impactos negativos na qualidade dos deslocamentos urbanos no referido município. Enquanto a velocidade operacional mínima desejada seria de $20 \mathrm{~km} / \mathrm{h}$, os veículos do transporte coletivo em Goiânia operam, em média, a $11 \mathrm{~km} / \mathrm{h}$. Para melhoria deste cenário, a RMTC afirma que seriam necessários, no mínimo, $150 \mathrm{~km}$ de corredores; no entanto, são existentes em Goiânia apenas 32,6 $\mathrm{km}$ de corredores (RMTC, 2017 apud UFG e SECIMA, 2017).

Apesar de o aparato legislativo estar voltado para o estabelecimento de condições que deem prioridade ao transporte coletivo (e também ao não motorizado), o cenário da mobilidade e da acessibilidade na RMG se caracteriza por uma expressiva ausência de priorização e investimento público no sistema de transporte coletivo. Além disso, a dispersão desenfreada da ocupação do solo urbano contribui para a perda de qualidade na oferta destes serviços. Associados às facilidades para aquisição de veículos particulares, fatores como esses estimulam a perda de demanda no transporte público. Entre os anos de 2015 e 2016, a RMTC sofreu queda de $12 \%$ na sua demanda de passageiros (UFG e SECIMA, 2017). 
De acordo com o Denatran, dentre as cidades com maiores frotas de carros, Goiânia ocupa a sexta posição, com 605 mil automóveis. Quanto às motocicletas, a capital ocupa a quarta posição, com total de 1,8 milhão (DENATRAN, 2017). Enquanto a população na capital é estimada em 1.495.705 habitantes (IBGE, 2018), observa-se que há mais carros e motos do que pessoas no município. Além do aumento da emissão de poluentes, bem como da ocorrência de acidentes, o aumento dos congestionamentos configura um preocupante ciclo vicioso que agrava as condições de mobilidade e acessibilidade das pessoas na região. O aumento do número de veículos em circulação nas vias e o consequente aumento dos congestionamentos reduzem ainda mais a velocidade operacional dos veículos do transporte coletivo. Com isso, o aumento do tempo de viagem, somado à outros fatores que comprometem a qualidade do serviço de transporte público contribui para que o usuário abandone o transporte público e passe a utilizar diariamente o veículo motorizado individual. Como resultado, observa-se repetido aumento do número de veículos em circulação e um agravamento nas condições de mobilidade e acessibilidade.

A partir dessa problemática, este trabalho encontra no uso de indicadores uma ferramenta de suma importância para uma compreensão mais detalhada e específica acerca da acessibilidade na RMG. Sendo assim, ao explorar dados relativos a tempo gasto e distância percorrida nos deslocamentos metropolitanos da RMG e; com isso, quantificar dados que expressam características acerca do panorama da referida região, este trabalho contribui ao disponibilizar informações que podem colaborar para a elaboração de diagnósticos, bem como a sugestão de medidas para melhorias.

\section{Aplicação dos indicadores de acessibilidade na RMG}

O indicador proposto por Allen et al (1993) foi aplicado a partir dos fatores tempo e distância. O formato global do referido indicador avaliou a acessibilidade dos municípios em sua totalidade, como um conjunto. No formato integral, por sua vez, a avaliação considerou uma relação par a par entre os municípios. As equações que formulam o referido indicador são as seguintes:

$$
\begin{gathered}
A_{i}^{\prime}=\frac{1}{n-1} \sum_{\substack{j=1 \\
j \neq i}}^{n} I_{i j} \\
E=\frac{1}{n} \sum_{i=1}^{n} A_{i}^{\prime}=\frac{1}{n(n-1)} \sum_{i=1}^{n} \sum_{\substack{j=1 \\
i \neq 1}}^{n} T_{i j}
\end{gathered}
$$

Onde:

$\mathrm{A}^{\prime} \mathrm{i}=$ acessibilidade integral normalizada

lij = fator impedância (tempo em minutos/distância em km) entre os locais i e j

$\mathrm{n}=$ número de locais

$\mathrm{E}=$ acessibilidade global

Além das medidas espaciais, um segundo indicador, do tipo gravitacional, foi utilizado de maneira complementar. Indicadores desse tipo, por sua vez, permitem 
análises mais profundas na medida em que acrescentam às características do transporte outras relativas ao uso e à ocupação do solo. Para tanto, foi aplicado o indicador proposto por Hansen (1959), tendo o emprego como o fator de oportunidade que contribui para a geração de viagens. A equação referente a esse indicador é a seguinte:

$$
A_{i}=\sum_{j=1}^{n} \frac{W_{j}}{f(C i j)}
$$

(Eq. 03)

Onde:

$A i=$ acessibilidade da zona $i$

$W j=$ número de oportunidades no destino $j$

$F(C i j)=$ função de impedância ao deslocamento no espaço

A coleta dos dados foi realizada através da ferramenta Google Maps, que oferece informações em tempo real sobre o itinerário e os tempos de viagens do transporte público, bem como as distâncias percorridas. A RMTC utiliza o Google Maps como ferramenta de roteirização, de maneira a disponibilizar dados relativos ao planejamento antecipado de viagens. Dessa maneira, busca-se facilitar a visualização dos trajetos, integrações e o tempo real de duração de cada viagem (RMTC, 2018). Esta característica revela confiabilidade com relação aos dados disponíveis na plataforma Google Maps. Os dados de tempo, em minutos, foram coletados em dias úteis do mês de outubro de 2016 entre as $07 \mathrm{~h}$ e $08 \mathrm{~h}$. O indicador global de Allen et al. (1993) calculado para a RMG resultou na seguinte relação, expressa na Figura 4.

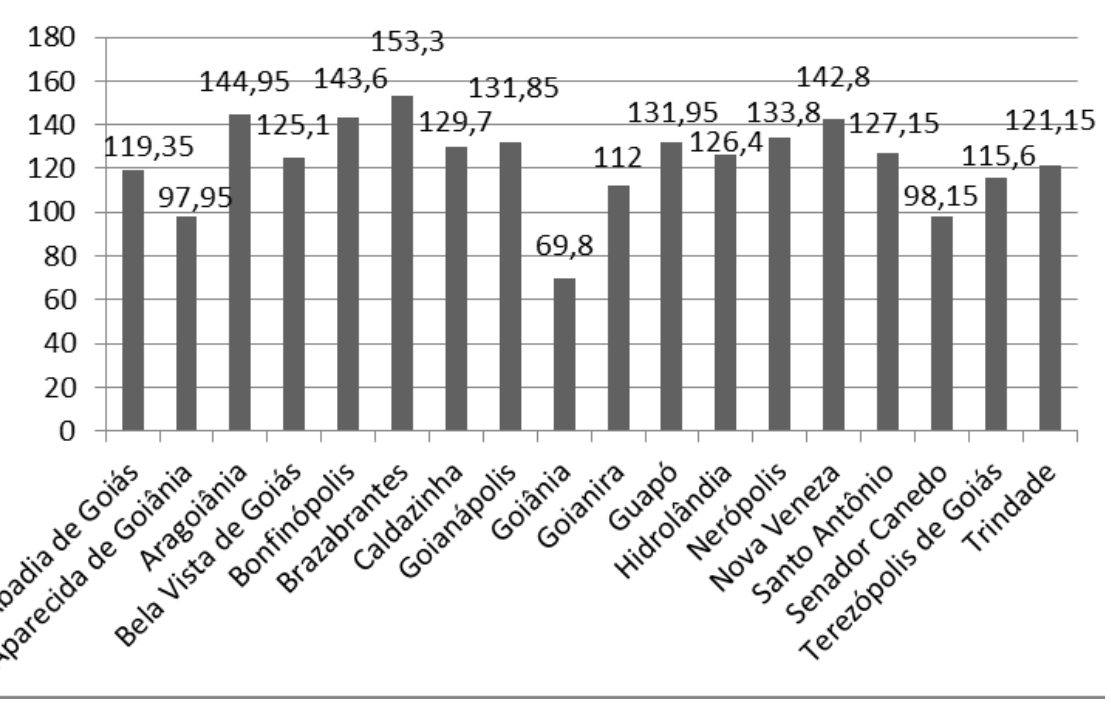

Figura 4. Resultado do Indicador Global de acessibilidade com base no tempo gasto em deslocamentos por transporte público na RMG. Fonte: própria.

Conforme ilustra a Figura 4, o indicador global baseado no fator tempo comparou entre si os 18 municípios atendidos pelo serviço de transporte público da RMTC. Cabe ressaltar que os municípios com índices mais elevados representam piores condições 
de acessibilidade. Sendo assim, Aparecida de Goiânia, Goiânia e Senador Canedo apresentaram os melhores resultados, enquanto Aragoiânia, Bonfinópolis e Brazabrantes tiveram os piores.

De maneira geral, esse mesmo indicador, aplicado sobre o tempo gasto em viagens por automóvel apresentou melhores condições de acessibilidade para todos os municípios. A Figura 5, a seguir, traz um comparativo entre os resultados obtidos através da aplicação do indicador de acessibilidade com base no tempo gasto entre viagens por automóvel e viagens por transporte público coletivo. Destaca-se que, quanto ao tempo gasto em viagens metropolitanas na RMG, o automóvel tem oferecido às populações condições de acessibilidade superiores em comparação ao TPC. Por outro lado, essa constatação também aponta para um quadro preocupante: o uso excessivo de automóveis na RMG, que contribui significativamente para o aumento dos congestionamentos, poluição e acidentes de trânsito, prejudica a mobilidade e acessibilidade bem como a qualidade de vida nas cidades que absorvem tais fluxos.

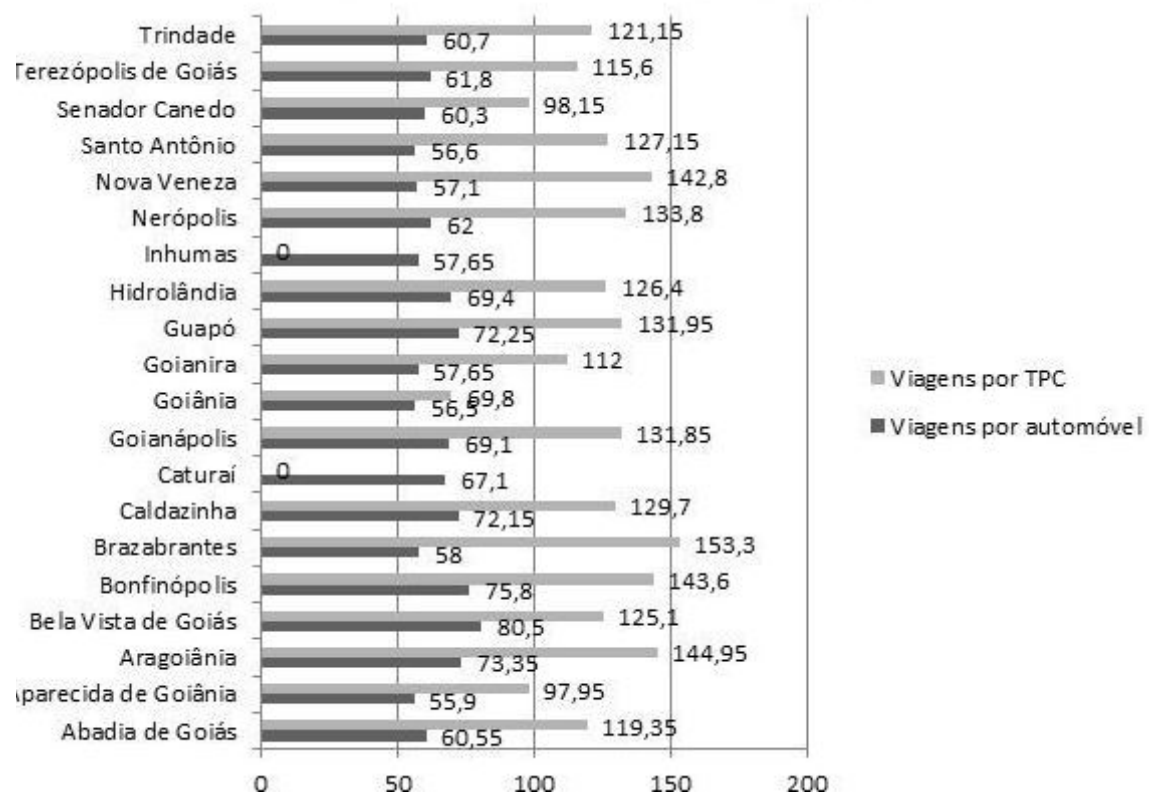

Figura 5. Comparativo dos indicadores de acessibilidade global com base no tempo gasto (TPC $\mathrm{x}$ transporte individual). Fonte: própria.

Ao observar o indicador global de Allen et al. (1993) aplicado com base na distância percorrida pelo transporte público, verifica-se um resultado diferente do obtido no indicador baseado no tempo gasto. A Figura 6 sintetiza tal informação. 


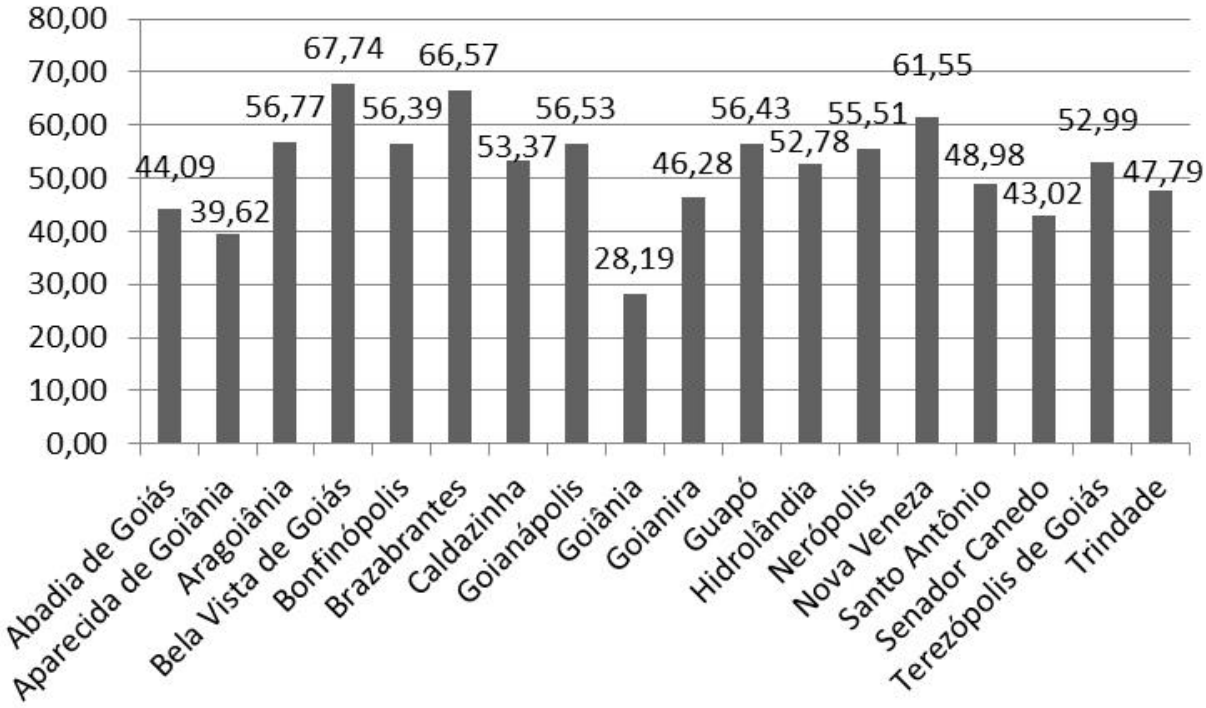

Figura 6. Resultado do Indicador Global de acessibilidade com base na distância percorrida em deslocamentos por transporte público na RMG. Fonte: própria.

No ranking dos indicadores de acessibilidade, os municípios com melhores e piores condições variaram conforme adotou-se o tempo ou a distância como fatores de impedância. A comparação entre os resultados indica que, no contexto da acessibilidade, nem sempre se aplica a proporção matemática entre as grandezas tempo e distância.

No caso da distância percorrida, os municípios de Bela Vista, Brazabrantes e Nova Veneza apresentaram os piores resultados, enquanto Goiânia, Aparecida de Goiânia e Senador Canedo tiveram os melhores. Neste caso, os municípios com melhor acessibilidade são coincidentes com o resultado obtido com base no tempo gasto nos deslocamentos.

Cabe destacar que, juntos, Goiânia, Aparecida de Goiânia e Senador Canedo representam quase $90 \%$ de todo o quantitativo populacional da RMG. De acordo com o Ipea (2015), estes municípios são considerados como de porte elevado e têm destaque nas atividades industriais, no potencial turístico e também atuam como sede ou participante de arranjo produtivo local articulado. Além dessas vocações e potencialidades, Senador Canedo também se destaca no âmbito da produção principal no campo da agropecuária. Outro município que também apresenta estas características vocacionais é Trindade (IPEA, 2015).

No entanto, o IPEA (2015) destaca que, na RMG, Goiânia, Aparecida de Goiânia e Senador Canedo são os municípios que recebem os maiores investimentos privados e que possuem prefeituras com melhores condições financeiras, enquanto Trindade ainda apresenta baixo dinamismo econômico, consideráveis carências sociais e prefeitura com baixas condições financeiras. No estado de Goiás, Goiânia e Aparecida de Goiânia estão entre os municípios que mais recebem pessoas de outros municípios em movimentos pendulares, sendo o mercado de trabalho, os estabelecimentos educacionais e os serviços de saúde as atividades mais atrativas para tal fenômeno. Em 2010, estudos de tipologia de deslocamentos pendulares identificou que Goiânia é o grande receptor de fluxos, enquanto Aparecida de Goiânia é o grande evasor (IPEA, 2015). Em 2016, os valores de PIB (Produto Interno Bruto) per capita registrados por estes municípios foi de, respectivamente, $\mathrm{R} \$ 32.209,01$ e R $\$ 22.514,94$. Impactado pelo 
Polo Petroquímico da Petrobras, Senador Canedo registrou PIB per capita no valor de R $\$ 33.136,31$ (IBGE, 2018). Somados, os valores de PIB desses três municípios correspondem a cerca de $20 \%$ do total do PIB da RMG. Tamanho desenvolvimento pode indicar significativo reflexo nos deslocamentos metropolitanos, o que se mostra coerente com os resultados obtidos na aplicação dos indicadores de acessibilidade realizada neste trabalho.

Quanto aos municípios com resultados que revelaram condições piores de acessibilidade, Aragoiânia, Bonfinópolis e Brazabrantes revelaram que os tempos gastos em viagens por TPC para os demais municípios da RMG são os mais elevados. No caso de Brazabrantes, esta relação também se aplica sobre as distâncias percorridas tendo como destinos os demais municípios da RMG. Nesse caso, mostra-se mais coerente a existência de condições piores de acessibilidade tanto para a distância quanto para o tempo gasto nas viagens.

Conforme dados do Ipea (2015), Aragoiânia está entre os municípios com menores taxas de urbanização da RMG: abaixo de 75\%. Esta característica também se relaciona com a vocação econômica do município, que tem como principais atividades a produção agropecuária e a industrial. No entanto, assim como Bonfinópolis, Aragoiânia é considerado de baixo dinamismo econômico e com grau considerável de carências sociais. Apesar da também reduzida integração ao núcleo metropolitano, Aragoiânia obteve crescimento geométrico anual da população residente em torno de $2,7 \%$ entre os anos de 2000 e 2010. Apesar disso, os valores de PIB per capita de ambos os municípios são relativamente baixos: R $\$ 10.318,54$ para Aragoiânia e R \$ 8.096,93 para Bonfinópolis, o que, somados correspondem a apenas 4,4 \% do PIB per capita de toda a RMG (IBGE, 2018).

Cabe destacar que a RMG tem apresentado um fenômeno de crescimento das regiões periféricas e desaceleração da fatia populacional das regiões centrais. O peso populacional do núcleo da RMG tem reduzido ao apresentar crescimento anual de $1,8 \%$, enquanto a periferia tem crescido $3 \%$ ao ano (Ipea, 2015). Se desacompanhado de ações estratégicas que ofereçam atividades diversificadas, dentre elas o emprego, em tais regiões periféricas, este crescimento pode tornar ainda maior a dependência desses municípios com aqueles que oferecem maiores quantitativos e tipos de atividades.

Como instrumento complementar à análise do indicador de Allen et al. (1993) o indicador de Hansen (1971) foi aplicado considerando a existência de empregos formais urbanos como fator atrativo de viagens aos municípios. A Figura 7, a seguir, apresenta dados referentes aos quantitativos de empregos formais, população e a relação emprego por habitante. Destacam-se os municípios de Bonfinópolis, Aragoiânia e Caturaí, que apresentaram as menores ofertas de empregos formais com relação aos seus quantitativos populacionais e, portanto, maiores taxas de habitantes por emprego. 


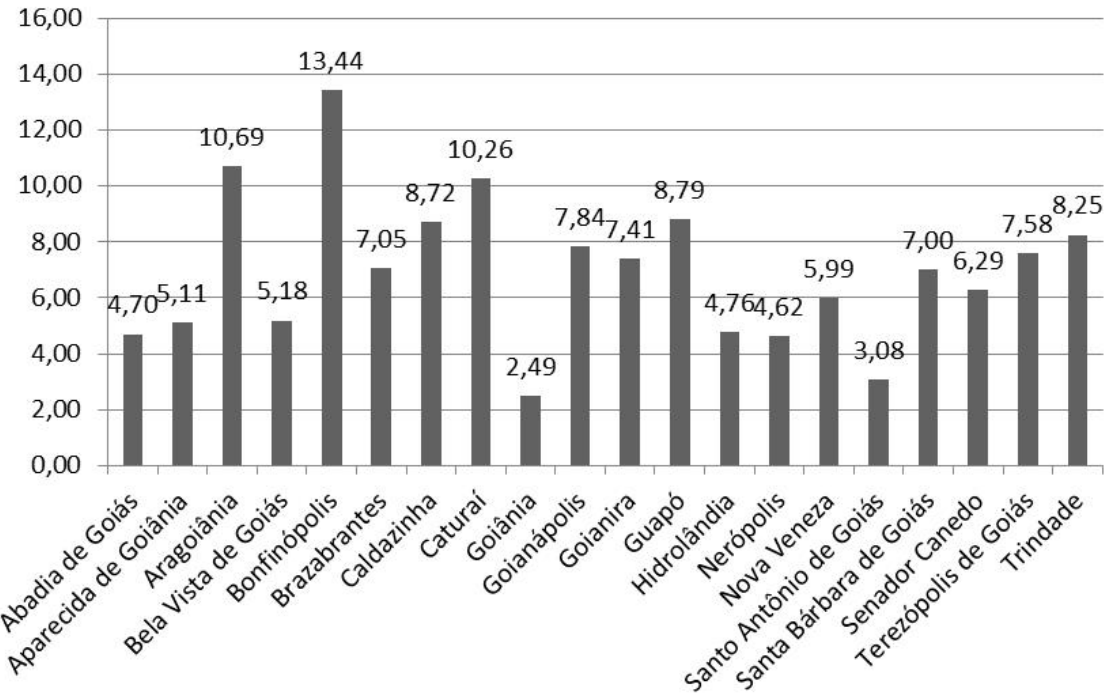

Figura 7. Relação habitantes por emprego formal nos municípios da RMG (2017). Fonte: adaptado de Ministério do Trabalho e IBGE (2018).

A partir da aplicação do indicador de acessibilidade com base no fator emprego, também foi utilizada a ferramenta estatística de desvio padrão; o que possibilitou observar a variabilidade segundo a qual se apresentam os referidos dados. No cálculo da Equação 3, o coeficiente de variação geral dos valores resultantes foi de 0,4 tendo o tempo como fator de impedância. Para o fator distância, o coeficiente de variação geral foi um pouco menor: 0,36. Conforme Medri (2011), coeficientes de variação de até 0,2 (ou $20 \%$ ) representam distribuições homogêneas. Os resultados obtidos para o caso da RMG apontam, portanto, um panorama de desequilíbrio na relação entre a existência de emprego e os tempos gastos para acesso a eles na região.

O indicador de acessibilidade global baseado tanto no tempo quanto na distância revelou que o município de Goiânia é o mais acessível. Nas análises par a par com base no tempo gasto, ou seja, no indicador integral, observa-se que, tendo Goiânia como destino, as melhores condições de acessibilidade foram identificadas para origens em Senador Canedo, Terezópolis de Goiás e Santo Antônio de Goiás. Apesar disso, uma estimativa dos movimentos pendulares em nove dos municípios da RMG realizada pelo IBGE - Instituto Brasileiro de Geografia e Estatística -, e pelo IMB - Instituto Mauro Borges - e, aponta que o maior número de habitantes que trabalham ou estudam em município diferente do de sua moradia são os de Aparecida de Goiânia (20.163 estudam; 88.718 trabalham; 6.824 estudam e trabalham) (Resende, 2017), conforme mostra o Quadro 1. 
Quadro 1. Estimativa da população e movimentação pendular acima de 15\% do total de habitantes na RMG (2010). Fonte: IBGE (2010); IMB (2012).

\begin{tabular}{|l|c|c|c|c|c|c|}
\hline Município & $\begin{array}{l}\text { Estimativa } \\
\text { da } \\
\text { população } \\
\text { total }\end{array}$ & $\begin{array}{l}\text { Estuda em } \\
\text { município } \\
\text { diferente }\end{array}$ & $\begin{array}{l}\text { Trabalha } \\
\text { em } \\
\text { município } \\
\text { diferente }\end{array}$ & $\begin{array}{l}\text { Estuda e } \\
\text { trabalha } \\
\text { em } \\
\text { município } \\
\text { diferente }\end{array}$ & $\begin{array}{l}\text { Total da } \\
\text { população } \\
\text { pendular }\end{array}$ & $\begin{array}{l}\text { População } \\
\text { pendular } \\
(\%)\end{array}$ \\
\hline Senador Canedo & 84.443 & 3.118 & 20.836 & 1.147 & 25.101 & 29,7 \\
\hline Goianira & 34.060 & 1.108 & 7.527 & 365 & 9.000 & 26,4 \\
\hline $\begin{array}{l}\text { Aparecida de } \\
\text { Goiânia }\end{array}$ & 455.657 & 20.163 & 88.718 & 6.824 & 115.705 & 25,4 \\
\hline Abadia de Goiás & 6.876 & 238 & 1.284 & 81 & 1.603 & 23,3 \\
\hline Bonfinópolis & 7.536 & 224 & 1.385 & 64 & 1.673 & 22,2 \\
\hline $\begin{array}{l}\text { Santo Antônio } \\
\text { de Goiás }\end{array}$ & 4.703 & 115 & 768 & 34 & 917 & 19,5 \\
\hline Trindade & 104.488 & 3.057 & 16.227 & 780 & 20.064 & 19,2 \\
\hline Brazabrantes & 3.232 & 217 & 361 & 42 & 620 & 19,2 \\
\hline Caldazinha & 3.325 & 116 & 417 & 18 & 551 & 16,6 \\
\hline
\end{tabular}

Ainda com relação aos resultados do indicador de acessibilidade integral com destino à Goiânia (maior receptor de fluxos), os municípios com piores condições de acessibilidade foram: Aragoiânia, Bonfinópolis e Brazabrantes. Conforme demonstrado no Quadro 1, suas populações pendulares correspondem a, respectivamente, 14\%, 22,2\% e 19,2\% (IBGE, 2010; IMB, 2012), o que revela significativa dependência destes municípios com relação aos que oferecem maiores quantitativos de emprego.

\section{Conclusões}

A análise dos resultados dos diferentes indicadores de acessibilidade aplicados na RMG permitiu identificar um panorama de desequilíbrio na referida rede. Enquanto o indicador de Allen et al. (1993) envolveu dados espaciais de tempo e distância, o de Hansen (1971), do tipo gravitacional, adicionou o fator emprego como oportunidade de deslocamento entre os municípios da RMG. Tais análises, juntamente com informações adicionais sobre os municípios, mostraram que o desequilíbrio identificado se dá a partir de fatores como a insuficiência na oferta de empregos em alguns dos municípios da RMG, o que tem contribuído para a geração de movimentos pendulares como resultado da busca de parte da população por atividades essenciais (como o emprego e a educação) em outros municípios.

O desequilíbrio entre a disponibilidade de empregos e moradias nos municípios da RMG contribui para uma configuração em que, de um lado, se inserem as chamadas cidades dormitório e, por outro, os municípios com fortes características de centralidade. Estes, ao receberem fluxos intensos de viagens oriundas de outros municípios podem comprometer a qualidade de vida de suas populações caso não considerem os fluxos pendulares em seus planos de mobilidade. No caso da RMG, observa-se que, dentre os critérios de escolha de um local de emprego, as excessivas distâncias a serem percorridas diariamente nem sempre se tornam uma barreira, tendo em vista a insuficiência de oportunidades em seus municípios de origem e a essencialidade de tal atividade na vida das pessoas, conforme demonstrado no Quadro 1. Por outro lado, ainda que existam municípios mais acessíveis quanto ao aspecto distância, o tempo gasto em deslocamentos diários pode comprometer a acessibilidade das pessoas bem como a sua qualidade de vida. Nesse sentido, cabe citar que os municípios de Aragoiânia 
e Bonfinópolis, apesar de não terem apresentado os piores resultados com relação à acessibilidade baseada na distância percorrida, estiveram entre os três municípios menos acessíveis da RMG com base no tempo gasto.

Além dos indicadores, o uso da ferramenta estatística do desvio padrão possibilitou observar que os municípios de toda a RMG apresentam baixa homogeneidade quanto à distribuição de uma atividade essencial para a vida urbana: o emprego. Ao não oferecer empregos suficientes, as populações residentes das cidades dormitório se direcionam, diariamente, para desenvolver atividades em outros municípios. Além de contribuir para uma maior demanda por viagens pendulares, esta prática também diminui a vitalidade das cidades menores, reforçando, assim, seu caráter de cidade dormitório.

Além do desequilíbrio no uso do solo metropolitano, a falta ou insuficiência de medidas que priorizem o transporte público contribui significativamente para o agravamento das condições de acessibilidade. Na RMG, a perda de demanda que o transporte público vem sofrendo nos últimos anos é um dos reflexos da insatisfação das populações com relação aos serviços de transporte público oferecidos. Essa perda de demanda, por sua vez, está associada, dentre outros aspectos, à uma migração dos usuários de transporte público para veículos motorizados individuais, o que confere ser uma tendência ameaçadora para a acessibilidade e mobilidade urbana principalmente nos municípios identificados como grandes receptores de fluxos pendulares.

Nesse sentido, o estudo de caso desenvolvido neste trabalho revela que o uso de indicadores de acessibilidade mostra ser ferramenta eficiente na elaboração de diagnósticos, mas também contribui com o planejamento de regiões metropolitanas, o que se faz fundamental para a elaboração dos Planos de Desenvolvimento Integrado, conforme estabelece o Estatuto da Metrópole (Presidência da República Brasileira, 2015). No que tange à acessibilidade, os indicadores utilizados neste trabalho contribuem para a elaboração de diagnósticos e para a indicação de medidas que podem ser eficazes para a melhoria da acessibilidade e mobilidade urbana, desde que seja dada prioridade ao transporte público frente aos modos individuais motorizados e que haja integração entre os diversos modais como a bicicleta e o transporte a pé.

Além disso, a elaboração de uma Pesquisa Origem-destino (OD) se faz de extrema importância para Goiânia e sua região metropolitana. Tendo a mais recente pesquisa OD sido realizada em 2000 apenas para o município de Goiânia, a desatualização de dados tão importantes inviabiliza estudos mais aprofundados sobre os deslocamentos das pessoas dentro de suas cidades bem como sobre os movimentos pendulares na RMG. Por outro lado, este trabalho mostra que, apesar da ausência de dados mais específicos e aprofundados, é possível obter análises e diagnósticos a partir do uso de indicadores de acessibilidade que envolvem dados de fácil acesso (como o tempo e distância das viagens metropolitanas) e que, somados a outras informações, podem contribuir significativamente nos processos de planejamento e gestão das cidades e regiões metropolitanas com vistas a melhorar as condições de acessibilidade e mobilidade de suas populações. 


\section{Q Bibliografía}

» ABNT - Associação Brasileira de Normas Técnicas (2015). ABNT NBR 9050 Acessibilidade a edificações, mobiliário, espaços e equipamentos urbanos. Rio de Janeiro: Comitê Brasileiro de Acessibilidade. Terceira edição. ISBN 978-85-0705706-2.

» Allen, W.B., Liu, D. Singer, S. (1993). Accessibility measures of U.S. metropolitan areas. Transportation Research Part B: Methodological, 27b (6), 439-449.

»ANTP - Associação Nacional de Transportes Públicos (2018). Mobilidade Humana para um Brasil Urbano. Brasil: ANTP. Recuperado de: http://www.antp. org.br/noticias/destaques/livro-mobilidade-humana-para-um-brasil-urbanoda-antp-faca-o-download-aqui.html, acesso em janeiro de 2019.

" Barat, J. (1978). Industrialização, urbanização e política de transportes: uma formulação para o desenvolvimento da Região Metropolitana do Rio de Janeiro. Rio de Janeiro: Banco Nacional de Desenvolvimento Econômico - BNDE.

"Bruinsma, F. e Rietveld, P. (1998). The accessibility of European cities: theoretical frameworkand comparison of approaches. Em: Environment and Planning A, 30, p. 499-521.

»Cardoso, L. Matos, R. (2007). Acessibilidade urbana e exclusão social: novas relações, velhos desafios. X Simpurb - X Simpósio Nacional de Geografia Urbana - Florianópolis: Universidade Federal de Santa Catarina.

"Costa, M. da S. (2008). Um índice de mobilidade urbana sustentável. Tese de Doutorado. Escola de Engenharia de São Carlos da Universidade de São Paulo - São Paulo.

» DENATRAN - Departamento Nacional de Trânsito (2017). Frota. Brasil: DENATRAN. Recuperado de: https://www.denatran.gov.br/frota.htm, acesso em janeiro de 2019.

» Ferraz, A. C. P. e Torres, I. G. E. (2001). Transporte Público Urbano. São Carlos: Editora Rima.

"Bertucci. J. de O. (2011). Os benefícios do transporte coletivo. Em: C. W. de A. Oliveira (Ed.), Boletim Regional, urbano e ambiental do IPEA (77-88). Brasília: Instituto de Pesquisa Econômica Aplicada - IPEA.

»Estado de Goiás (2018). Lei Complementar 139, de 22 de janeiro de 2018. Goiânia: Secretaria de Estado da Casa Civil.

»Estado de Goiás (2019). Lei Complementar 149, de 15 de maio de 2019. Goiânia: Secretaria de Estado da Casa Civil.

"Hansen, W. (1959). How accessibility shapes land use. Journal of the American Institute of Planners, 25 (2), 73-76.

" IBGE - Instituto Brasileiro de Geografia e Estatística (2018). Goiânia. Brasil: IBGE. Recuperado de: https://cidades.ibge.gov.br/brasil/go/goiania/panorama, acesso em janeiro de 2019.

" IBGE - Instituto Brasileiro de Geografia e Estatística (2010). Censo demográfico - Famílias e domicílios - Resultados da amostra. Brasília: Ministério do Planejamento, Orçamento e Gestão. 
» IMB - Instituto Mauro Borges de Estatísticas e Estudos Socioeconômicos (2012). Mobilidade pendular da população em Goiás. Goiânia: Secretaria de Gestão e Planejamento do Estado de Goiás.

»Ingram, D. R. (1971). Gettin there: urban transportation in context. Em: S. Hanson (Ed.), The geography of urban transportation. New York/London: The Guilford Press.

"IPEA - Instituto de Pesquisa Econômica Aplicada (2015). Caracterização e quadros de análise comparativa da Governança Metropolitana no Brasil: análise comparativa das funções públicas de interesse comum (componente 2). Rio de Janeiro: IPEA.

" ITDP - Instituto de Políticas de Transporte e Desenvolvimento (2016). Desafios e oportunidades para a expansão do transporte de média e alta capacidade no Brasil. Brasil: ITDP. Recuperado de: http://2rps5v3y80843iokettbxnya.wpengine. netdna-cdn.com/wp-content/uploads/2016/03/paper-policy-pbu-21-03.pdf, acesso em julho de 2019.

» Jones, S. R. (1981). Accessibility measures: a literature review. Crowthorne: Transport and Road Research Laboratory. Department of the Environment. Department of Transport Laboratory Report 967.

"Mello, A.J.R. (2015). A acessibilidade ao emprego e sua relação com a mobilidade oe desenvolvimento sustentáveis: o caso da Região Metropolitana do Rio de Janeiro. Tese de Doutorado, COPPE, Universidade Federal do Rio de Janeiro. Rio de Janeiro.

» MCidades-Ministério das Cidades (2008). A Mobilidade Urbana no planejamento da cidade. Brasília: Ministério das Cidades.

" MCidades - Ministério das Cidades (2007). PlanMob Construindo a Cidade Sustentável: Caderno de Referência para Elaboração de Plano de Mobilidade Urbana. Brasília: Secretaria Nacional de Transporte e da Mobilidade Urbana.

»Medri, W. (2011). Análise Exploratória de dados. Londrina: Centro de Ciências Exatas, Departamento de Estatística. UEL - Universidade Estadual de Londrina.

» Ministério do Trabalho (2018). CAGED. PDET - Programa de Disseminação das Estatísticas do Trabalho. Brasil: Ministério do Trabalho. Recuperado de: http:// pdet.mte.gov.br/caged?view=default, acesso em julho de 219.

» Mitchell, G. (1996). Problems and fundamentals of sustainable development indicators. Sustainable Development. 4 (1), 1-11.

» Motte-Baumvol, B.; Nassi, C. D.; Belton-Chevallier L. (2015). Barriers and (im) mobility in Rio de Janeiro. Urban Studies, (53) 2956-2972.

»Mueller, C.; Torres, M.; Morais, M. (1997). Referencial básico para a construção de um sistema de indicadores urbanos. Brasília: Instituto de Pesquisa Econômica Aplicada (IPEA).

» Ortúzar, J. D.S; Willumsen. L.G. (2001). Modelling Transport. New York: John Wiley \& Sons.

"Portugal, L. da S. (2017). Transporte, mobilidade e desenvolvimento urbano. Organização: Licínio da Silva Portugal. 1 ed. Rio de Janeiro: Elsevier.

»Prefeitura de Goiânia (2007). Plano Diretor de Goiânia. Lei Complementar 171, de 29 de maio de 2007. Goiânia: Câmara Municipal de Goiânia.

»Prefeitura de Goiânia (2012). População residente segundo os municípios da Região Metropolitana de Goiânia e do Estado de Goiás 2000-2010. Brasil: 
Prefeitura de Goiânia. Recuperado de: https://www.goiania.go.gov.br/shtml/ seplam/anuario2012/arquivos\%20anuario/3\%20DEMOGRAFIA/3.1\%20 Popula\%C3\%A7\% $3 \% \mathrm{~A}_{30} / 3.1 .18 \% 20$ Popula\%C3\%A7\%C3\%A30\%20da\%20 Regi\%C3\%A30\%20Metropolitana\%20-\%202000-2010.pdf.

»Presidência da República Brasileira (2012). Política Nacional de Mobilidade Urbana. Lei 12.587, de 3 de janeiro de 2012. Brasília: Presidência da República, Casa Civil.

»Presidência da República Brasileira (2015). Estatuto da Metrópole. Lei 13.089, de 12 de janeiro de 2015. Brasília: Presidência da República, Casa Civil.

»Raia Junior, A. A. (2000). Acessibilidade e Mobilidade na Estimativa de um Índice de Potencial de Viagens Utilizando Redes Neurais Artificiais e Sistemas de Informação Geográfica. Tese de Doutorado, Universidade de São Paulo - São Carlos.

" Resende, U. (2017). As contradições e os desafios da mobilidade urbana de Goiânia no contexto de sua Região Metropolitana. Tese de Doutorado, Universidade Federal de Goiás - Goiânia.

" RMTC (2016). RMTC Goiânia. Brasil: RMTC. Recuperado de: http://www. rmtcgoiania.com.br/sobrea-armtc/informacoes-institucionais, acesso em julho de 2016.

» RMTC (2018). I-Center. Brasil: RMTC. Recuperado de: http://www.rmtcgoiania. com.br/sim/icenter, acesso em janeiro de 2018.

"Sales Filho, L. de H. (1998). O uso de indicadores de acessibilidade na avaliação de redes estruturais de transporte urbano. Rio de Janeiro: Instituto Serzedello Corrêa.

» Santos, L. S. (2009). Análise da influência da variação espacial da oferta de um modo de transporte público urbano no comportamento de viagem de seus usuários. Dissertação de Mestrado de Engenharia Civil e Ambiental, Faculdade de Tecnologia da Universidade de Brasília - Brasília.

"SECIMA - Secretaria de Estado de Meio Ambiente, Recursos Hídricos, Infraestrutura, Cidades e Assuntos Metropolitanos (2018). O que é a Região Metropolitana de Goiânia. Brasil: SECIMA. Recuperado de: http://www.secima. go.gov.br/cidades-e-assuntos-metropolitanos-2/regi\% $\mathrm{C}_{3} \% \mathrm{~A}_{30}$-metropolitanade-goi\%C3\%A2nia.html, acesso em janeiro de 2018.

»Shields, D.; Solar, S.; Martin, W. (2002). The role of values and objectives in communicating indicators of sustainability. Ecological Indicator. 2(1), 149-160.

» Taaffe, E. J., Gauthier, H. L.; O’Kelly, M. E. (1996). Geography Of Transportation. New Jersey: PrenticeHall.

» Teixeira Filho, J. L. L. (2009). Análise da variabilidade do tempo de viagem como fator de impacto nos custos logísticos do transporte de carga. Rio de Janeiro: COPPE - Universidade Federal do Rio de Janeiro.

" UFG e SECIMA (2017). Plano de Desenvolvimento Integrado da Região Metropolitana de Goiânia - Análise da Mobilidade Urbana e Metropolitana. Goiânia: Universidade Federal de Goiás, Secretaria de Estado de Meio Ambiente e Desenvolvimento Sustentável.

»Veras, D. F. G. Pinto, G. F. N. Lobo, C. F. F. Cardoso, L. Garcia. R. A. (2016). Acessibilidade urbana em Belo Horizonte: apontamentos sobre a acessibilidade aos serviços de transporte coletivo municipal. $7^{\circ}$ Congresso Luso Brasileiro para o Planejamento Urbano, Regional, Integrado e Sustentável - Contrastes, contradições e complexidades: Maceió. 


\section{Ana Stéfany da Silva Gonzaga / anastefany.arq@gmail.com}

Graduada em Arquitetura e Urbanismo (UFG) e com mestrado pelo Programa de Pós-Graduação Projeto e Cidade (UFG). Professora (UFG) e pesquisadora (UFG) nos temas relacionados com transportes, mobilidade, acessibilidade e centralidades.

\section{Érika Cristine Kneib / erikacristine@gmail.com}

Graduada em Arquitetura e Urbanismo (UFES), mestre e doutora em Transportes (UNB). Desenvolveu pesquisa de pós-doutorado no tema mobilidade urbana, no Instituto Superior Técnico de Lisboa - IST. Professora e pesquisadora (UFG) no curso de Arquitetura e Urbanismo e no Programa de Pós-Graduação Projeto e Cidade. Exerceu atividades relacionadas com planejamento urbano, transportes e mobilidade urbana em prefeitura municipal, no governo do Distrito Federal e no Ministério das Cidades. 